\title{
A History of Women's Homelessness: The Making of a Crisis
}

\author{
Abe Oudshoorn \\ Western University \\ Amy Van Berkum \\ Western University \\ Colleen Van Loon \\ Western University
}

\begin{abstract}
Women's homelessness is continually referred to as a new, surprising, or growing phenomenon. Rather, in this paper we explore the proposition that women's homelessness has long existed in Canada, Australia, the United States of America and the United Kingdom, but in many ways has been ignored or marginalized. To do so, we use texts, articles, and reports from the mid-1800's to today to present how women experiencing homelessness are pushed to the margins of an already marginalized group. Instead of a new phenomenon, we seek to demonstrate that women's homelessness has evolved over time parallel with evolving gender roles. Ultimately, we conclude that it is in fact structural forces of gender that have put women at unique risk of experiencing hidden homelessness.
\end{abstract}

Keywords: Homelessness, gender, history, women, homeless

To tell history is to tell a story. No history is inherently complete, each author must pick and choose what pieces they tell and what pieces are left out. Which perspectives are privileged, which issues are explored, which sources are trusted, and which lens is used to attribute motives to actions may vary significantly with each author. When researching history some aspects might be easier to discover, others more hidden, and others completely lost in time. There is no such thing as a 'definitive' history of any particular event, theme or issue, rather there are multiple histories that reflect attempts at accuracy, yet are skewed by the perceptions of the author. In telling a history of women's homelessness a key focus area is gender. This review seeks to highlight the existence of women's homelessness over the last two centuries, and the gendered nature of this phenomenon. This is a meaningful focus, as while popular depictions of homelessness tend to feature men, research supports that women constitute a significant portion of those who have experienced homelessness throughout history. Women who have experienced homelessness become homeless as a result of a system that is not designed to intentionally de-house them, but as a natural outcome of an unfavorably gendered system.

A historical review of women's homelessness begins with outlining key contributing factors within the mid-1800's and the period of rapid industrialization of western nations, including Canada, Australia, the United States of America (USA), and the United Kingdom (UK). This timeline was selected as the mid 1800's represents the shift from agrarian society to industrial

Corresponding author: Abe Oudshoorn (aoudshoo@gmail.com) 
society, which shapes our current understanding of women's homelessness. It is worth acknowledging that women's homelessness has existed throughout history (Golden, 1992). A historical review reveals there is a misconception between our current understanding of 'home' and previous understandings. Migration to cities, single family homes, major urban populations, and large rental markets that emerged in the mid-1800s continue as trends today.

This historical review is complicated by the perpetually hidden nature of women's homelessness, both from women themselves hiding their experiences, and from systems and services under-acknowledging women among those who are homeless. Women's hidden homelessness takes many forms, from women transients disguising their gender for protection (Golden, 1992), to women avoiding living in slums (Serbulo, 2003) where formal counts of homelessness were conducted, to tens of thousands of women living in brothels not considered to be experiencing homelessness (May, Cloke \& Johnsen, 2007), to single women and their children experiencing homelessness, to women avoiding more visible but dangerous activities such as panhandling in public spaces (Wardhaugh, 1999), and to research neglecting the experiences of Indigenous women. People experiencing homelessness have been pushed to the margins and at times ignored, and women are a sub-set of the population who have experienced this more acutely. This review serves in part to bring the experiences of women's homelessness to the forefront.

\section{Search Methodology}

Diverse search strategies were utilized to uncover literature, particularly information prior to the advent of most scholarly journals. We began with research databases to uncover any existing literature on the gendered nature of homelessness, and the history of women and housing or homelessness. Search strings included: ((women* OR female OR woman OR mother* OR gender) AND (homeless* OR housing OR hobo OR tramp OR vagrant OR rough sleep*)) OR family homelessness) AND (Canada OR Australia OR (United States OR U.S. OR USA OR U.S.A. OR America*) OR (Britain OR United Kingdom OR U.K. OR UK OR England OR Scotland OR Wales OR *Ireland)). We reverse searched sources from these articles, uncovering a variety of historical texts, including both reports and books. We utilized library search engines and Google Books to uncover other texts, as well as cold searching through the oldest books on social issues, poverty, homelessness, gender, and urban issues in our local university library. Finally, a Google search on women's homelessness, housing, women's shelters, and gender and poverty was used to uncover any articles or texts missed in other search techniques. We limited the search to literature from Canada, Australia, the USA, or the UK, as similarities in the development of gender roles and in social issues make these countries a logical fit for comparative analysis, and we were limited in only having fluency in the English language.

Following an overview of historical perspectives of womanhood, the paper is organized chronologically using literature from the era or other historical analyses of the eras. Each section opens with a consideration more broadly on gender roles and shifting laws or perspectives on gender, before moving into considerations of poverty and homelessness, then particularly for women and homelessness in that era. Where policies or their outcomes are particular to one of the nations of study, this is indicated, where no particular nation is identified, the issue is considered common across the four nations of study.

\section{Historical Perspectives on Womanhood}

The history of homelessness among women is not the same as the history of homelessness among men (Klodawsky, 2006). Consider the social construction of what it meant to be a woman in the Victorian era (1837-1901). During this period, women throughout developed and developing nations were people without rights: no right to own property, no right to vote, no 
right in many cases to legal recourse, no right to decisions about their body, no right to divorce, and no right to family finances if they were married (Bailey, 2007). Over time laws were changed in most countries granting rights to women, however, this was often resisted both culturally and socially. Historically, the role of a woman was only understood in relation to her male counterpart (Green \& Perry, 1983). The ideal woman was perceived to be married, often at a young age and arranged to some degree, and occupied the role of a home-maker and mother (Beeton, 1861). The concepts of 'woman' and 'home' were intimately intertwined, meaning that women who were experiencing homelessness had been structured within a social order at the heart of the Victorian family. A woman without a home was perceived to be an affront, a deviant (Casey, Goudie \& Reeve, 2008), and a corruption of the design of both the state and the Church.

Two responses can be seen as the natural fallout from the under-acknowledgement of women's homelessness. The first is to criminalize the experience, to see it as social deviance or a flaw in need of correction, which will be presented in depth throughout this history. The second is to simply ignore or deny that such a situation might exist. In 1957, Catholic theologian Dr. Elfan Rees declared the $20^{\text {th }}$ century "The Century of the Homeless Man" (Rees, 1957), effectively ignoring the plight of millions of women who experience homelessness globally. Bahr and Garrett (1976) suggest that women's homelessness is not perceived by the general public, therefore not brought to the attention of politicians and researchers as a social problem to be addressed (Garrett \& Bahr, 1976). Or, if women's homelessness has been recognized as a social concern, it is not considered to carry the same social risk as men's homelessness, which is often associated with crime and other risky behaviours. This same challenge is encountered when researching the history of women's homelessness. There are many histories of homelessness written, however, they overwhelmingly prioritize the plight of men, focusing on policies and programs created for men's homelessness, and even providing statistics solely on men. Some of this challenge is rooted in the reality that many more women are in situations of hidden homelessness rather than visible or absolute homelessness, yet as we hope this history will show, various versions of supports serving under-housed women have always existed and the people they support have been available to share their stories should governments, researchers, or historians think to ask. It is more likely that the sexism that has under-pinned academic research in general, leading to women being vastly under-studied in comparison to men (Kelly \& Cordell, 1996), is also seen with studies on people experiencing homelessness.

Preceding laws have depicted women as second-class citizens, lacking 'personhood'. For example, women were not afforded such a designation by law in Canada until the Privy Council decision in 1929 (Marshall \& Cruikshank, 2006), and the full right to vote in Australia until the Commonwealth Franchise Act of 1902. Not only has this limited women's access to housing, it has silenced women experiencing homelessness altogether. The recommendation for women to be acknowledged as an important sub-group within the socially constructed concept 'homelessness', and for their unique support needs to be redefined within the context of this social problem, will allow for both progressive and equitable measures taken in solving homelessness.

\section{Women's Homelessness in the Late Victorian Era and Early Twentieth Century}

Throughout the Victorian era (late 1800s and early 1900s), women in Canada, Australia, the UK, and the USA were perceived as wives, mothers, and home-makers. Therefore, a woman's identity was dependent of her relationship with male counterparts. Women were expected to transition in their late teens or early twenties from 'daughter' to 'wife' with marriage rates for women exceeding 90\% (Anderson, 2006). Independence was perceived as either a form of rebellion or a form of dishonor to patriarchal traditions. Although women might have been 
heavily engaged in various forms of labour, such as agriculture, food preparation, production of clothes or household goods and other tasks, this was primarily conducted within the confines of the family unit. Women in Australia were not granted a full adult wage until 1974 . In 1901, Canada reported that only $13 \%$ of workers were women (Connelly, 2006). The majority of these workers were engaged in low pay work, such as clothing manufacturing, domestic service, or agriculture for those in rural areas. However, there are notable examples of women at this time taking leadership roles in Canada, such as Adelaide Hoodless, author and educational reformer who helped found the Victoria Order of Nurses (VON) and Young Women's Christian Association (YWCA); Luce Cuvillier store-owner and landlord; and Emily Stowe, the first female physician to practice in Canada. Women's rights in Australia preceded other nations by a few years in many ways, with Catherine Helen Spence being the first female candidate for office in 1897. However, the majority of these women came from families of significant privilege and wealth. There is little doubt that their social statuses afforded them some leniency in stepping outside of strictly enforced gender norms. The one significant shift in the social construction of the role of women at this time was the opening of the educational system. In 1842 , only $23.1 \%$ of Canadian girls were engaged in education and by 1881 this had risen drastically to $75.6 \%$ (Anderson, 2006). This change would be one of the factors that would lead to significant shifts in gender roles moving into the twentieth century.

The complexity of how various social constructions impacted both the role of women and their housing status during this time are well illustrated by the differences in attitudes towards mainstream labour and sex work. In the UK in the late 1800s (Watson \& Austerberry, 1986) and America in the early 1900s rescue homes were developed in order to assist women who were seen to have stepped outside of societal norms, often labeled as 'fallen' or 'depraved' (Hellegers, 2011). These homes were meant less as a space of charity or a solution to housing loss and more as a means of rehabilitation, to re-train women on how to fit 'appropriately' within society, such as encouraging marriage and their domestic role within the family unit (Hellegers, 2011). Some women were taken into rescue homes for the sole reason of being single, adult women engaged in the work force (Serbulo, 2003). The assumption was clear, a woman working independently was in need of reform, even if it meant removing her from her current home. At the same time, sex work existed in a state of semi-permissibility. In many cities across Canada, Australia, the UK, and the USA, anti-prostitution laws were not formalized until the 1910s and 1920s (Bedford, 1981). Sex workers provided a perceived necessary service for men that was granted more leniency than, for example, a woman attempting to be a licensed physician or lawyer (Weber, 2009). It is not a coincidence that lower paying and more dangerous employment for women was more accepted at this time. This misogyny can be observed today as women are far less represented on corporate boards and holding elected government positions as compared to men (Paxton \& Hughes, 2016).

Poverty in Canada, Australia, the USA, and the UK in 1850-1920 had its extremes, with the lack of public healthcare systems and social security equating to the risk of death by malnutrition or simple communicable diseases. Overall average life expectancy in Canada in 1900 was under 50 years (Norris \& Williams, 2000), with those experiencing poverty being much shorter, although no formal statistics on life expectancy were collected prior to the 1960s. At this time, poverty was perceived to be a deserved condition of fallen persons and an appropriate punishment for a life of sloth, sin, or crime (Lees, 1998). As such, people experiencing poverty were subject to arrest and/or taken against their will into workhouses. This was enabled by the creation of Poor Laws, such as the Vagrancy Act in New South Wales (NSW), Australia, which formally criminalized those without work or without a home. In most cities, sleeping rough was considered sufficient grounds for incarceration (Lees, 1998). Providing charitable support to the poor was a contested issue and little to no reward was afforded by society for such personal failings (Golden, 1992).

A variety of housing options existed for those experiencing abject poverty. These included housing attached to temporary or permanent factory work, rooming or boarding houses, 
brothels for women engaged in sex work, or various clustered sub-standard housing within slums or skid rows. It should be noted that women staying in mixed boarding houses with men went against social norms and was considered a form of deviance (Watson, 1999). However, because of vagrancy laws that led to incarceration of people sleeping rough, and the availability of remarkably low-cost housing options, visible street homelessness was relatively rare at this time. The issue was less about being unhoused and more about being underhoused. These low-cost and sub-standard options were provided primarily through the private market, with the first government-subsidized social housing in Toronto, Canada not opening until 1913 (Layton, 2008). Although charitable organizations provided some housing options, most of these were considered rescue or reform homes and were meant to 'fix' people. In Australia, the Salvation Army opened the first maternity home in 1903 called the 'Open Door Maternity Home'; and in Canada they opened their first home in 1898 in Saint John's and through the early 1900s they operated 13 rescue homes across Canada for sex workers (Sawyer, 2014). These housing options were as much geared at altering the perceived deviance of women formerly sharing low-cost accommodations with men as they were about providing dignity and support (Sawyer, 2014).

During this time, women's homelessness within urban settings was both hidden from society and underestimated in statistics. Although women were heavily engaged in sex work, this was largely perceived as a profession of choosing that involved some form of housing, therefore they were not considered homeless. Women who lived in slums most frequently fulfilled gender-based roles of housekeeping or servant-hood in the broader community (Serbulo, 2003). Slums were largely perceived as unsafe for women and to be avoided if possible. Areas where homelessness was identified, such as streets and alley ways, were less likely to be frequented by women who were without a stable home environment (Serbulo, 2003).

\section{Women's Homelessness Between the Wars (1918-1938)}

World War I represented a significant shift in employment and women were brought into the workforce to replace men who went off to fight in the war. There was an economic need to continue to extend current production demands as well as meet new demands caused by the war. Wages for women were significantly lower than those for the men they replaced, and most employment opportunities were in low-skilled, higher risk jobs. Following the war there was a shift to then remove women from these workplaces, and legislation to prevent this discrimination such as the 'Sex Disqualification (Removal) Act of 1919' in the UK was rarely utilized (BBC, 2017). This demonstrated the slow progression of social change. It was considered increasingly more acceptable for women to be employed outside the home; however, only as a secondary option to that of the primary income-earner, their male counterpart. For many, the period between the world wars was a reversion back to imposed domestic roles and the economic dependence of women on men. The perceived return to the family household ignored the fact that many women who had found work had not been married prior to the on-set of the war, or had become recently widowed because of the war (Wilson, 2002). For others, they were able to find some degree of precarious employment in migratory work, either seasonal or temporary work, and were part of the marginalized population known as 'hobos', 'travelers', 'transients', or 'migrants'. Women were particularly vulnerable in this type of work with many reporting experiences of serial rape, and using clothing to disguise their sex (Watson, 1999). A 1935 survey identified only 2-3\% of migrant workers as women (Watson, 1999) yet these surveys also included a large number of persons of 'undetermined gender', most likely women.

This period also provides economic contradictions. Industrialization was thriving, producing mass amounts of capital, nonetheless this new wealth was primarily gained by business owners, almost entirely men. This was exacerbated by the Great Depression in the 1930s where income inequality peaked throughout the industrialized world. The working class 
experienced mass poverty while many property, resource, and factory owners saw significant profits (Piketty \& Saez, 2003). A number of factors heightened the experience of urban poverty including rural to urban migration. With industrialization, employment through the 1800 s and 1900s became increasingly centralized in urban areas and to this day we see a continued migration of Canadian, Australian, American, and British populations from agricultural areas to cities. Simultaneous to this influx of new urbanites at a time of high poverty and low employment was the lack of social spending. Public healthcare and social assistance, including housing allowances, did not exist at this time, and it was expected that the charitable sector would suffice to serve the needs of those experiencing homelessness. Religious and secular charities were unable to keep pace with the demands of the population. These concurrent forces contributed to both significant insufficiency in housing and a lack of affordability for available housing, leading to ongoing expansion of slum districts (Layton, 2008). During this period, the homeless problem was on the rise with 1.25 million Americans estimated to have experienced homelessness, with between $30-50 \%$ of these being women (Golden, 1992).

Women living on the margins were trapped in a crisis of poverty and lack of social services. The services that did exist focused, almost exclusively, on the imposition of moralistic perspectives on what was deemed as women's deviance (Hellegers, 2011). Vagrancy laws were fully enforced at this time, such as newly formed laws against street-involved or brothelbased sex work (Watson \& Austerberry, 1986). Displays of mental health challenges in public were also criminalized and considered a frequent justification for incarceration. In these early days of psychology and psychiatry, women were at significant risk of being pathologized as mentally ill by male physicians (Ussher, 1991). The incarceration of women experiencing poverty with the excuse that they were 'mad' presents one of the most compelling examples of misogyny in action. It also demonstrates why women's homelessness throughout time has continued to remain hidden and women in poverty were frequently being forcefully removed from public spaces. In regards to aid for women in poverty, there was a shift at this time from the development of rescue homes in general to the development of maternity homes, geared towards single women who were pregnant. Not all women brought to these homes were necessarily homeless or even experiencing poverty, but it does represent a small shift from homes of correction to homes of support. This type of support existed largely because of the strong moralistic attitudes against pregnancy outside of marriage (Kunzel, 1988).

\section{Women's Homelessness Post World War II (1945-1960)}

After the Second World War, industrialized English-speaking nations began a significant process of urban and suburban renewal that carried on into the 1960s. In Australia, this included a massive shift of rural populations to urban areas, particularly suburbs. With large population shifts at the end of the war, housing was in demand, leading to rapid development of new housing. One of the most significant demographic shifts is referred to as the "baby boom'. For instance, the birth rates in the USA were nearly twice the rate of today (Greenwood, Seshadri \& Vandenbroucke, 2005). This meant that housing supply was in high demand for cities, also referred to as 'post-war housing' in the 1950s. However, the vast majority of new housing development during this period was at market rent, rather than accommodating individuals with low-income. Additionally, home ownership skewed almost entirely towards men. Despite generally strong economies throughout developed nations and a rapid increase in housing stock, attempts to obtain permanent housing remained a struggle.

The post-World War II era represented a period when income inequality was less divided. Two key factors contributed to this: 1) High rates of lucrative employment, including increasingly for women, across all sectors including manufacturing, related to the lack of external market competition; and, 2) New systems of income distribution, such as the New Deal in the USA (Saez, 2009), to support those through hardships. An increasing number of women benefited 
from the rise of employment. By 1950, 34\% of women in the USA were represented in the labour force (Status of Women in the States, 2017). Although most professions were formally open to women, significant prejudice continued to block women from access to the highest paid professions or they were paid less for doing equal work when compared with men (Status of Women in the States, 2017).

For those living in poverty and experiencing homelessness, the post-war era saw a shift from housing emergency services that were merely focused on behavioural reform to providing basic housing needs (Bhugra, 2007). This shift meant less reformatory structures and more transitional spaces of housing support provided to individuals. That is not to suggest that stigmas regarding the causes of homelessness altered, but that services were provided more universally under a welfare model versus a moral reform model. Provision of emergency and temporary housing options became more concrete and, combined with a strong economy, very little is written about absolute homelessness or street homelessness during this generation. This limited media or academic coverage of homelessness has been used to suggest that homelessness was somehow eliminated during this period until the 1970s. However, various shelter and rooming houses continued to exist, along with the continuation of substandard and temporary living conditions, creating a large presence of hidden homelessness. In the era of 1945-1960, homelessness was more hidden due to stronger community supports and a stronger economy. This hiddenness is also reflective of how we seek to categorize people in a single way: 'sex worker' or 'criminal' or 'poor' versus 'homeless', rather than realizing that people can experience homelessness while also enacting a variety of other identities.

An expanding welfare system at this time did not necessarily benefit women and men equally. For example, post-war home-building in the UK under the 'Homes for Heroes' program focused on the needs of men or nuclear families (Miller, 1990). This meant that single women who were homeless continued to access substandard lodging houses, which were often of poor condition. Women were not equally benefited from increased assets of home-ownership when compared to men. During this time, UK's social housing system consisted of new developments that were two or three bedroom 'family' units, as municipally legislated to provide accommodation focused only on families (Miller, 1990). This continued to reify traditional beliefs about women as ideally married and with children. Indigenous women have faced issues of home-ownership most acutely, with the Indian Act in Canada prioritizing status for men until 1985, and status being a requirement of home ownership on reserves (Callaghan et al., 2002).

\section{Women's Homelessness in the 1960s}

One of the most significant forces effecting housing and homelessness through the 1960s was shifts in costs of urban housing. Four particular factors have contributed: 1) The economy continued to remain relatively stable; 2) Leading to urban renewal, such as gentrification; 3) While communities undertook the elimination of slums; and 4) Support for new municipal legislation. Although the pace of economic growth slowed somewhat, growth was still the trend and this was largely shared across various income levels (Saez, 2009). After the development of new suburbs occurred through the 1950s and the growth of the baby boom population continued, there was a shift by families and professionals to purchase core and near-core neighbourhoods that had been areas of poverty or explicitly slums. 'Urban Renewal' became the driving force that led to large-scale elimination of rooming or boarding houses, and the complete elimination of most slums in countries such as Australia and Canada. This included advocacy on human rights and contesting existing sub-standard housing. Building codes were updated under the Local Government Act of 1958 in Australia, and 1961 heralded the introduction of the municipal fire department codes in Canada that served as a key tool in phasing out sub-standard housing. 
Many governments used social housing development to ensure that individuals and families were not displaced as former sub-standard housing was slowly being replaced by market housing. Subsequently, the 1960s was a time of a rapid increase in the development of new social housing. The intention was that new social housing developments would conform to building and fire codes, and adequately house all of those in need, regardless of sex or gender. This approach would be funded and led by governments, rather than being dependent on charitable organizations. The growth in social housing paralleled a general increase to the social safety net. For example, the Canadian Assistance Plan Act in 1966 brought greater consistency of access to social security, tying together components of old age security, children's benefits, and unemployment benefits. Additionally, the first family shelter in Canada opened in 1965 in the City of Hamilton, and the first 'modern' women's shelter in the USA, Haven House, opened in 1964 in California. What is most notable in this shift is the decline of moralistic attitudes that saw social services as a means for moral reform to a perception that all members of society have a right to receive the basic necessities of life.

The increased availability of social services raises the question of whether homelessness existed throughout the 1960s. Although more people could now access affordable and quality housing, rescue homes and emergency shelters continued to operate and experience need. It is of some significance that the emergency shelter in Hamilton, which opened in 1965, focused on the needs of homeless families, reflecting the ongoing trend to prioritize the needs of homeless women and their children. There exists personal autobiographies of homelessness experienced in the 1960s indicating that despite progress that might have been made by offering social housing and income supports, there was still a failure to house all people (Garrett, Volk, Caplow \& Bahr, 1970).

For women, the late 1960s is known for the start of the women's liberation movement and second wave feminism (Thompson, 2002). The movement played a significant role in addressing homelessness in the 1970s and beyond. Firstly, second wave feminism had a strong communal component with women organizing themselves formally or informally. These circles, collectives, bookshops, university departments, houses, and other forms of organizing would become or would drive the development of the shelters and drop-in centres of the 1970s (Kane, 2017). Secondly, a significant portion of the new dialogue driven by second wave feminism was focused on issues of violence, rape, and domestic violence. This led to the formation of personalized support services for women experiencing homelessness over the next several decades. Unfortunately, women of colour and Indigenous women were not always included in the development of these support services (Thompson, 2002).

\section{Women's Homelessness in the 1970s}

The 1970s was a decade of competing ideologies. Liberal and socially progressive ideologies were enacted through action on human rights, while traditional and socially conservative ideologies continued to frame gender roles. Human rights conflicts began in the 1960 s and continued to evolve into the 1970s, including rights around gender, sexuality, race, and disability. For instance, there was a newly progressive approach to deinstitutionalize individuals with mental health challenges (Golden, 1992), who were often forced into an asylum or asylum-like systems. Grounded both in a rights-based perspective of mental health care (Pathare, 2003) that prioritized least-intrusive means, and in opportunities afforded by new medications, it was seen that people could live far more independently in the community than previously assumed if afforded the right supports. However, there were unintended consequences of integrating a human rights perspective into mental health care. Over time it became clear that as enacted, the deinstitutionalization process was problematic as individuals were met with insufficient supports within the community (Lamb \& Bachrach, 2001). The aftermath of such inadequate processes has become a social problem which still currently 
exists. That is, there is an over-representation of people with mental health challenges among those who are chronically homeless, both women and men (Fazel, Geddes \& Kushel, 2014).

While rights for women were part of the movements of the 1960s and 1970s, there were also attempts to keep women in traditional gender roles. In the 1970s, workforce participation for women was only $38 \%$ as opposed to $62 \%$ for men. From 1960 to 1980 , single person households increased from $9 \%$ to $27 \%$ in Canada (Statistics Canada, 2015). 'Non-married' women were still perceived as a measurable deficit, a form of social isolation throughout Canada, Australia, the USA, and the UK. At a time when a lack of research existed, Garrett and Bahr (1976) aimed at shedding light on the experiences of homeless women. The authors described women's homelessness as a 'sociological mystery' and hypothesized that most women who were homeless were coming from 'broken homes', meaning homes without both a male and a female parent, with 'never having been married'. Alcoholism among women was labeled as a form of 'deviance' and individual 'problems' were causes of homelessness. Systemic and structural factors contributing to the social problem were denied. The discourse within the article around women's homelessness demonstrates the ongoing tendency towards traditional gender norms within the 1970s.

Tension between traditional and progressive foci were displayed in how development of supports for people experiencing homelessness were situated. Government funded supports returned to a focus on 'deservedness'. For example, the 1977 Housing (Homeless Persons') Act in the UK contained language around people's 'intentionality' of becoming homeless (Miller, 1990). Similar language had been used by various social housing providers, and further excluded women and children fleeing domestic violence (Miller, 1990). The assumption was that women who left a relationship, regardless of violence, were intentionally homeless and did not qualify for housing supports (Watson \& Austerberry, 1986). Contradictory to this individualistic focus, as the feminist movement expanded, many collectives supported the opening of the first women's shelters, such as Elsie Refuge in NSW, Australia in 1974, Boston in 1974 (Golden, 1992), and violence against women (VAW) shelters in Vancouver, Langley, Calgary, Toronto and Saskatoon in 1973 (Tutty, 1998). These shelters were less patriarchal, and recognized the common experience of domestic violence among women experiencing homelessness; they were created by women and for women.

While Australia stands as an outlier with the greatest quantity of social housing built between 1945-1956, for Canada, the UK, and USA, social housing development continued rapidly through the early 1970s (Layton, 2008), and peaked in the mid-1970s. For example, in Canada the Minister of Urban Affairs introduced new Housing legislation affirming that all Canadians need to be adequately housed in "good housing at a reasonable cost and is a social right of every citizen in this country" (Basford, 1973, p. 2257) in an attempt to respond to the widespread poverty at hand. While there was an increase in housing stock, there was also increased gentrification/urban renewal, displacing people from inner city neighbourhoods (Brushett, 2001). Unfortunately, the development of new social housing began to decline towards the close of the decade (Watson \& Austerberry, 1986). With that said, continued stressors on the availability of affordable housing options, and a cultural shift that enforced earlier oppressive-like values, especially for women, the late 1970 s paved the way for the homelessness crisis of the 1980s.

\section{Women's Homelessness in the 1980s}

Hulchanski, Campsie, Chau, Hwang and Paradis (2009) frame the 1980s as the rise of homelessness in Canada. Hope and Young (1986, p. 17) stated that in the USA "the popular media began to discover the homeless in the early 1980s", however this is at a time when the federal estimate of homelessness already exceeded two million persons. Limbrick (2006, p. 4) notes that in the Australian context, "Awareness of the structural causes of homelessness 
accelerated during the recession of the 1980's and this was accompanied by recognition of new emerging types of homelessness among women, young people and families". Across Canada, Australia, the USA and the UK, the 1980s was a time of significant reduction in new or existing social housing, accompanied by a rise in visible homelessness. In London, UK, new social housing builds dropped from 21,147 to 2,490 with an additional existing 90,000 units sold off (Miller, 1990). People living in temporary accommodations rose from 5,000 in 1982 to 30,000 in 1989 . This was accompanied by a strong attitudinal shift with, for example, resistance to clauses allowing housing for pregnant women experiencing homelessness, with the argument that this might encourage pregnancy. These attitudes are paralleled in the USA at this time, with a belief that if shelters are too lenient or supportive of homeless persons it will lead to social comfortability, such as a place to seek attachment and belonging, and as an attractive alternative to paying rent, presuming that people have a choice in becoming homeless (Hope \& Young, 1986).

The 1980s in Canada witnessed an ongoing period of under-supply of affordable housing precipitated by government cutbacks starting in 1984 (Hulchanski et al., 2009). This included a $\$ 2$ billion federal reduction (Layton, 2008), with a funding cap in 1993 and subsequent downloading of social housing from the federal to the provincial level in 1996. Communitybased organizations were established to fill in the gap, specifically the lack of government intervention for social welfare issues, such as their inability to supply adequate housing within a growing economy (Evans, Hanlin \& Prilleltensky, 2007).

A Toronto community services survey in the early 1980 s found an overwhelming 3,400 known homeless persons (Van Vliet, 1988), however the authors note that this is likely a vast underestimate, and likely even more of an under-estimate for women. By the mid-1980s the United Nations (UN) declared 1987 as the International Year of Shelter for the Homeless (IYSH), recognizing the growing crisis of visible homelessness around the world (Oberlander \& Fallick, 1988). This period represented the greatest shift from hidden homelessness to visible homelessness, and the existence of women as a sub-population begins to be acknowledged. Van Vliet (1988) reported that women with children were the fastest growing sub-group of the homeless population. Merves (1992) confronts the mythology of the 'bag lady', and demonstrates that women's homelessness is as complex as men's. Hope and Young (1986) suggest that the narrowness of government definitions of homelessness that focus only on shelters and rough sleeping ignore hidden homelessness, highlighting how female travelers might conceal their sex for safety. One of the Canadian solutions profiled in the contribution to the IYSH report is second-stage housing for women in Winnipeg (Oberlander \& Fallick, 1988). Van Vliet (1988) highlights the concept 'feminization of poverty', in which single women and female-headed households are more likely to experience poverty. He further reports that in Canada by 1984 there were 165 emergency shelters for women fleeing violence, housing 18,000 women annually. Stoner (1983) reports 4,000 women experiencing homelessness in Orange County, California, highlighting the scope of women's homelessness in spite of the limited publicity or research on the issue. Sullivan and Damrosch (1987) highlight the diversity of women's experiences of homelessness, from families, to single women, to young women, and women leaving violence.

Although women's homelessness was being recognized during this period there was still a casual acceptance of homelessness as a personal phenomenon, excusing poor policy decisions and economic failures (Hulchanski et al., 2009). It prevented a shift in public perceptions as there was a continued tendency to miss the role of government supported housing in preventing homelessness (Hulchanski et al., 2009). The discourse of homelessness as a defining characteristic of an individual can still be seen in societal discourses on homelessness today (Schneider, 2014). 


\section{Women's Homelessness in the 1990s and Beyond}

The 1990s can be conceived as the decade of the 'charitable shelter'. While historical shelter statistics in Australia could not be obtained, in 1987 there were 472 combined shelters in Canada (McLaughlin, 1988), by 2016 there were 401 emergency shelters and 452 VAW shelters (Employment and Social Development Canada, 2016), with the majority built or started in the 1990s. Government cuts to new social housing in the 1980 s were followed by further cuts in the 1990s. Visible homelessness commencing in the 1980s continued unabated into the 1990s. This included a particular increase in Indigenous urban homelessness (Callaghan et al., 2002). In 1999, the Australian Government launched the National Homelessness Strategy in response to increased concerns. By 1998, in Canada, the Toronto Disaster Relief Committee declared homelessness a national disaster (Crowe \& Baker, 2007). The charitable sector responded to this crisis in the best way they perceived at the time: developing new emergency shelters. During this time, non-profit organizations were considered innovators and entrepreneurs, as these services identified missing gaps in community support for vulnerable groups (Cnaan \& Vinokur-Kaplan, 2015). In the USA, there was a parallel exponential expansion of prisons. For example, the number of persons in prison for drug offences increased from 41,000 in 1980 to 500,000 in 2011 (Hellegers, 2011). In many ways, prisons have become a new form of temporary housing for people experiencing homelessness and/or mental health challenges. Relating to the cultural attitudes of this time, people who were considered 'beggars' or 'street people' or the homeless were being arrested for public trespassing and being placed in jail for petty crimes (e.g., trespassing on public property) or fined (e.g., street activity fines) (Tutty, 1998). The rapid development of new emergency shelters, though charitable and well-meaning, in some ways, led to an entrenchment of homelessness in communities. A significant portion of public and charitable dollars to address homelessness shifted towards managing people while they were in an experience of homelessness, versus preventing or ending homelessness. It has since become evident that this system design is problematic. When shelters become the primary response service to homelessness and evolve into the sole care providers for long-term health and social outcomes of homeless individual, this serves to temporarily assist people versus supporting permanent re-housing (Montgomery, Szymkowiak, Marcus, Howard \& Culhane, 2016).

Throughout the 1990's, women continued to be overlooked in consideration of their experience of homelessness (Lenon, 2000), with the continued visual representation of homelessness being the middle-aged male with an alcohol addiction. Golden (1992) reported on a study on social workers that found 'a surprising number' of homeless women in Philadelphia, this despite the researchers themselves being involved in social work in the community. May and colleagues (2007) suggested that even throughout the 1990s, urban research on exclusion and homelessness continued to focus primarily or solely on experiences of men. They suggest that this is in part due to the hidden nature of women's homelessness (Casey et al., 2008). They also highlighted a 1999 survey of 15,000 female applicants for support from housing and homelessness agencies, a full $1 / 3$ of whom had slept absolutely rough at some point in their lives. Rather, they point out that one of the ways that women are rendered invisible is by deeming women as sex workers rather than homeless, when in fact many are both. They identify four important 'cartographies' of women's homelessness: 1) those distanced from homeless services and a homeless identity; 2) those in the shadows of the street; 3 ) those who are visibly homeless; and 4) sharing spaces of homelessness but often forgotten as homeless, for example, the street-involved sex worker.

Due to extreme government cutbacks in the 1980's, as outlined earlier, there still remains similar issues well into the $21^{\text {st }}$ Century. Emerging research has shown that charitable organizations developed by local communities as a result of government cutbacks, such as emergency shelters, are now outmoded in terms of supporting permanent exits from 
homelessness. While these organizations provide necessary emergency support, they have in turn become a part of the entrenchment of managing homelessness versus ending or preventing homelessness (Evans et al., 2007; Ramsundarsingh \& Shier, 2017). For women, this has included many current services lacking an essential trauma-informed lens to care. Trauma-informed practices involve supporting the capacity of clients by recognizing that trauma may have occurred throughout their experience that has led them to be homeless or during their experience and adjusting their organizational practices to manage individual trauma symptoms successfully (Shier \& Turpin, 2017). Many homeless-serving organizations have not considered women or integrated gender-based supports into programming. Women often come into homelessness as a direct result of domestic violence and abuse, however, when utilizing shelter or other services they are often connected with the same services that men use. This carries the risk of re-traumatizing women who have a history of abuse, which can lead women into other unsafe situations (e.g., rough sleeping or couch surfing). Lastly, health and social services are forced to compete for limited resources and funding, which negatively impacts marginalized populations by creating a sense of division between service providers all attempting to solve homelessness with scattered and limited resources. Homelessness is a structural problem and, therefore must be solved at a system level versus through programmatic responses.

\section{Conclusion}

In conclusion, we return to the title of Golden's (1992) work: Homeless Women Have Always Existed. Indeed, women have always experienced homelessness in Canada, Australia, the USA, and the UK, but the nature of this homelessness has shifted over time, largely in part due to shifting conceptualizations of gender. The clarity of defining homelessness as more than 'sleeping rough' or 'absolute homelessness' assists in seeing other forms of homelessness that have been more historically hidden. Whether temporarily housed in jail, brothels, boarding houses, emergency shelters, with friends, or sleeping rough, women have been an ignored sub-population of those experiencing homelessness. Shifts between being hidden and visibly homelessness are largely determined by public policy. However, governments and policy advancements, over time and moving forward, continue to inadequately provide a social safety net, such as developing new social housing and providing adequate housing supports. Indeed, rather than closing the gap, gender-based income inequalities are increasing in countries such as Australia (Workplace Gender Equality Agency, 2014). We propose that in post-industrial western nations, there are socio-structural barriers specific to women and housing. It is not just that people are homeless and some of them happen to be women, it is that to be a woman alters your risk of homelessness, your pathways into homelessness, opportunities for support once homeless, pathways out of homelessness, and perceptions of being home. This is a timely conclusion given two concerning phenomena: that women are often left out of discussions on who experiences homelessness; and that when women are acknowledged as also being at risk of homelessness, this is often expressed as some new or current phenomenon. If we fail to understand the ongoing nature of women's homelessness and the relationship both to gender and to social policy, we risk a lack of refinement in proposed responses to this social issue. 


\section{References}

Anderson, D. (2006). Status of Women. Retrieved May 23, 2017 from http://www.thecanadianencyclopedia.ca/en/article/status-of-women/.

Bahr, H. M. \& Garrett, G. R. (1976). Women alone: The disaffiliation of urban females. Lexington Books.

Basford, R. (1973). Introduction to the 1973 NHA amendments by the Minister of State for Urban Affairs, Canada, House of Commons, Hansard, March 15, 2257.

Bailey, J. (2007). 'English Marital Violence in Litigation, Literature and the Press'. Women's History, 19, 144-153.

BBC (2017). What Did World War One Really Do For Women? Retrieved May 23, 2017 from http://www.bbc.co.uk/guides/z9bf9j6.

Bedford, J. (1981). 'Prostitution in Calgary 1905-1914'. Alberta History, 29, 1-11.

Beeton, I. (1861). The Book of Household Management. Retrieved May 23, 2017 from http://www.gutenberg.org/cache/epub/10136/pg10136-images.html

Bhugra, D. (2007). Homelessness and Mental Health. Cambridge University Press.

Brushett, K.T. (2001). Blots on the Face of the City: The politics of slum housing and urban renewal in Toronto. Dissertation, Queen's University.

Callaghan, M., Farha, L., Porter, B., Fraser, J., Harraher, N., Mulgrave, M. \& Tingley, S. (2002). Women and housing in Canada: Barriers to equality. Toronto, Ontario, Canada: Centre for Equality Rights in Accommodation.

Casey, R., Goudie, R. \& Reeve, K. (2008). 'Homeless women in public spaces: Strategies of resistance'. Housing Studies, 23(6), 899-916.

Cnaan, R. A. \& Vinokur-Kaplan, D. (2015). 'Social innovation: Definitions, clarifications, and a new model'. Cases in innovative nonprofits: Organizations that make a difference, 116.

Connelly, M.P. (2006). Women in the Labour Force. Retrieved May 23, 2017 from http://www.thecanadianencyclopedia.ca/en/article/women-in-the-labour-force/.

Crowe, C. \& Baker, N. (2007). Dying for a home: Homeless activists speak out. Toronto, Ontario; Between the Lines.

Employment and Social Development Canada (2016). 2016 Shelter Capacity Report. Retrieved May 23, 2017 from https://www.canada.ca/en/employment-socialdevelopment/programs/communities/homelessness/publications-bulletins/sheltercapacity-2016.html.

Evans, S. D., Hanlin, C. E. \& Prilleltensky, I. (2007). 'Blending ameliorative and transformative approaches in human service organizations: A case study'. Journal of Community Psychology, 35, 329-346.

Fazel, S., Geddes, J. R. \& Kushel, M. (2014). 'The health of homeless people in high-income countries: descriptive epidemiology, health consequences, and clinical and policy recommendations'. The Lancet, 384(9953), 1529-1540.

Garrett, G. R. \& Bahr, H. M. (1976). 'The family backgrounds of skid row women'. Signs, 2(2), 369-381.

Garrett, G. R., Volk, D., Caplow, T. \& Bahr, H. M. (1970). Homeless Women in New York City: Observations at the Emergency Assistance Unit and Women's Shelter. Bureau of Applied Social Research, Columbia University.

Golden, S. (1992). The women outside: Meanings and myths of homelessness. University of California Press.

Green, H. \& Perry, M. E. (1983). The Light of the Home: An Intimate View of the Lives of Women in Victorian America. Pantheon.

Greenwood, J., Seshadri, A. \& Vandenbroucke, G. (2005). 'The baby boom and baby bust'. The American Economic Review, 95(1), 183-207.

Hellegers, D. (2011). No Room of Her Own: Women's Stories of Homelessness, Life, Death, and Resistance. Springer. 
Hope, M. \& Young, J. (1986). The Faces of Homelessness. Lexington Books, DC Heath and Co.

Hulchanski, J. D., Campsie, P., Chau, S. B., Hwang, S. W. \& Paradis, E. (2009). 'Homelessness: What's in a word' In Finding home: Policy options for addressing homelessness in Canada (e-book), Introduction. Toronto: Cities Centre, University of Toronto.

Kane, L. (2017). 'How a group of young feminists opened Canada's first shelter for abused women and children;. Toronto Star, retrieved May 23, 2017 from https://www.thestar.com/news/canada/2017/05/02/how-a-group-of-young-feministsopened-canadas-first-shelter-for-abused-women-and-children.html.

Kelly, P. J. \& Cordell, J. R. (1996). 'Recruitment of women into research studies: a nursing perspective'. Clinical Nurse Specialist, 10(1), 25-28.

Klodawsky, F. (2006). 'Landscapes on the margins: Gender and homelessness in Canada'. Gender, place \& culture, 13(4), 365-381.

Kunzel, R. G. (1988). 'The professionalization of benevolence: Evangelicals and social workers in the Florence Crittenton homes, 1915 to 1945'. Journal of Social History, 22(1), 21-43.

Lamb, H. R. \& Bachrach, L. L. (2001). 'Some perspectives on deinstitutionalization'. Psychiatric Services, 52(8), 1039-1045.

Layton, J. (2008). Homelessness: How to end the national crisis. Penguin Canada.

Lees, L. H. (1998). The solidarities of strangers: The English poor laws and the people, 17001948. Cambridge University Press.

Lenon, S. (2000). 'Living on the edge: women, poverty and homelessness in Canada'. Canadian woman studies, 20(3), 123.

Limbrick, D. (2006). 'Some reflections on the SAAP and homelessness in Australia'. Parity, 19(10), 4-5.

Marshall, T. \& Cruikshank, D.A. (2006). Persons Case. Retrieved May 23, 2017 from http://www.thecanadianencyclopedia.ca/en/article/persons-case/.

May, J., Cloke, P. \& Johnsen, S. (2007). 'Alternative cartographies of homelessness: Rendering visible British women's experiences of 'visible' homelessness'. Gender, Place and Culture, 14(2), 121-140.

McLaughlin, M. (1988). Homelessness in Canada: The Report of the National Inquiry. Canadian Council on Social Development.

Merves, E. S. (1992). 'Homeless women'. In Homelessness (pp. 229-244). Springer US.

Miller, M. (1990). Bed and Breakfast: Women and Homeless Today. Women's Press.

Montgomery, A. E., Szymkowiak, D., Marcus, J., Howard, P. \& Culhane, D. P. (2016). 'Homelessness, Unsheltered Status, and Risk Factors for Mortality: Findings From the 100000 Homes Campaign'. Public Health Reports, 131(6), 765-772.

Norris, S. \& Williams, T. (2000). Healthy Aging: Adding Life to Years and Years to Life. Science \& Technology Division, Government of Canada; PRB 00-23E.

Oberlander, H. P. \& Fallick, A. L. (1988). Homelessness and the Homeless: Responses and Innovations. A Canadian Contribution to IYSH 1987. Centre for Human Settlements, The University of British Columbia, Canada.

Pathare, S. (2003). Mental health legislation \& human rights (Vol. 5). World Health Organization.

Paxton, P. \& Hughes, M. M. (2016). Women, politics, and power: A global perspective. CQ. Press.

Piketty, T. \& Saez, E. (2003). 'Income inequality in the United States, 1913-1998'. The Quarterly journal of economics, 118(1), 1-41.

Ramsundarsingh, S. \& Shier, M. L. (2017). 'Anti-Oppressive Organisational Dynamics in the Social Services: A Literature Review'. British Journal of Social Work, 47, 2308-2327.

Rees, E. (1957). Century of the Homeless Man. Carnegie Endowment for International Peace; New York, NY.

Saez, E. (2009). Striking it richer: The evolution of top incomes in the United States (update with 2007 estimates). Working Paper, University of California Berkeley. 
Sawyer, B. (2014). A Critical History of Social Work, The Canadian Salvation Army, and Female Sexual "Deviance" in Canada, 1886-1940. Dissertation; University of Victoria.

Schneider, B. (2014). 'Homelessness: Emotion discourse and the reproduction of social inequality'. Canadian Journal of Communication, 39, 235-248.

Serbulo, L. C. (2003). Women Adrift, Sporting Girls and the Unfortunate Poor: A Gendered History of Homelessness in Portland 1900-1929. Dissertation, Portland State University.

Shier, M. L., \& Turpin, A. (2017). 'A Multi-Dimensional Conceptual Framework for TraumaInformed Practice in Addictions Programming'. Journal of Social Service Research, 43, 609-623.

Statistics Canada (2015). Distribution (in percentage) of private households by household size, Canada, 1961-2011. Retrieved May 23, 2017 from https://www12.statcan.gc.ca/census-recensement/2011/as-sa/98-312x/2011003/fig/fig3_1-4-eng.cfm.

Status of Women in the States (2017). Women's Labour Force Participation. Retrieved May 23, 2017 from https://statusofwomendata.org/earnings-and-the-gender-wagegap/womens-labor-force-participation/.

Stoner, M. R. (1983). 'The plight of homeless women'. Social Service Review, 57, 565-581.

Sullivan, P.A. \& Damrosch, S.P. (1987). 'Homeless women and children'. In R.D. Bingham, R.E. Green \& S.B. White (eds.) The Homeless in Contemporary Society. Sage Publications; Newbury Park, CA.

Thompson, B. (2002). 'Multiracial feminism: Recasting the chronology of second wave feminism'. Feminist Studies, 28(2), 337-360.

Tutty, L.M. (1998). Shelters for Abused Women in Canada: A Celebration of the Past, Challenges for the Future. Family Violence Prevention Health Issues Division Health Canada: Project \#H5227-7-K002.

Ussher, J.M. (1991). Women's madness: Misogyny or mental illness? University of Massachusetts Press.

Van Vliet, W. (1988). Women, housing, and community. Gower Pub Co.

Wardhaugh, J. (1999). 'The unaccommodated woman: Home, homelessness and identity'. The Sociological Review, 47(1), 91-109.

Watson, S. (1999). 'A home is where the heart is: engendering notions of homelessness'. (pp. 81-100). In Kennett \& Marsh (eds.), Homelessness: Exploring the New Terrain. Bristol, Britain, The Policy Press.

Watson, S. \& Austerberry, H. (1986). Housing and homelessness: A feminist perspective. Routledge.

Weber, K. (2009). 'Clara Brett Martin: Canada's First Woman Lawyer'. In the Hills, Spring 2009.

Wilson, E. (2002). Women and the Welfare State. London, Tavistock.

Workplace Gender Equality Agency (2014). Gender Pay Gap Statistics. Retrieved August 9, 2018 from https://www.wgea.gov.au/sites/default/files/2014-03-04Gender_Pay_Gap_factsheet_website.pdf.

\section{Biographical Notes}

Abe Oudshoorn, RN, PhD. Having worked as a nurse with people experiencing homelessness, Dr. Oudshoorn's research focuses on health, homelessness, gender, trauma, housing policy, and poverty. Outside of the University, Abe is past-Chair of the London Homeless Coalition, is a board member with the United Way of London \& Middlesex, and sat on the Mayor's Advisory Panel on Poverty. Abe is the recipient of Western University's 2016 Humanitarian Award. 
Amy Van Berkum, RN, MN. Women's homelessness became a research interest for Amy Van Berkum as she worked as a nurse alongside marginalized persons and explored the experience of trauma throughout her Master's in Nursing. Shortly thereafter, Amy spent time employed as a content writer and Research Coordinator focusing on efforts towards ending homelessness for women and girls alongside Dr. Oudshoorn and members of the greater London, ON. community.

Colleen Van Loon, MSW. Colleen Van Loon has supported individuals experiencing homelessness in her direct line work for over 10 years and continuing. Colleen's passion and motivation to make a difference in the field led her to complete a Master's in Social Work degree. Colleen was recently employed as a Research Coordinator with Dr. Oudshoorn and has since been accepted to the Health and Rehabilitation Sciences, PhD program. Colleen is also a Board Member with the London Poverty Research Centre where she continues to advocate for those who are often voiceless. 